\title{
Influence of high aluminium content on the mechanical properties of directionally solidified multicrystalline silicon
}

\author{
T. Orellana - E. M. Tejado - C. Funke \\ S. Riepe $\cdot$ J. Y. Pastor $\cdot$ H. J. Möller
}

\begin{abstract}
The purpose of this research is the mechanical characterisation of multicrystalline silicon crystallised from silicon feedstock with a high content of aluminium for photovoltaic applications. The mechanical strength, fracture toughness and elastic modulus were measured at different positions within the multicrystalline silicon block to quantify the impact of the segregation of impurities on these mechanical properties. Aluminium segregated to the top of the block and caused extensive micro-cracking of the silicon matrix due to the thermal mismatch between silicon and the aluminium inclusions. Silicon nitride inclusions reduced the fracture toughness and caused failure by radial cracking in its surroundings due to its thermal mismatch with silicon. However, silicon carbide increased the fracture toughness and elastic modulus of silicon.
\end{abstract}

\section{Introduction}

The use of alternative silicon feedstock has potential for reducing costs for photovoltaic applications. For example, less expensive substrates of up-graded metallurgical silicon are used as a mechanical support for the epitaxial solar cell [1]. This type of feedstock has a higher concentration of impurities that can lower the mechanical strength of the wafers [2]. To achieve high yield during the production of solar cells, it is important to quantify the impact of these impurities on the mechanical behaviour of multicrystalline silicon. Therefore, impurities that are deleterious for the mechanical strength of silicon wafers must be avoided

Cracks are the most harmful type of defect because stresses intensify at the tip of the cracks. In addition to microcracks, inclusions can also be fracture initiators [3] due to the thermal residual stresses introduced during processing and to the intensification of stress that occurs when an external load is applied in the surroundings of the inclusions. Furthermore, the same inclusion impurities change the elastic modulus of silicon and the stress intensity factor of a crack that approaches the inclusion. Therefore, quantifying the effect of inclusions on silicon fracture is of great importance for strength interpretation and failure prediction.

The impact of different types of impurities on the mechanical behaviour of multicrystalline silicon for photovoltaic applications is studied in this work. These impurities are aluminium, silicon nitride and silicon carbide. Bending tests, fracture toughness and elastic modulus measurements have been performed to cover a significant quantification of the impact of these impurities on the mechanical and fracture behaviour of silicon. The experimental results are compared with models of mechanical behaviour of ceramics from the early literature to achieve relevant failure prediction. 
Table 1 Concentration of impurities [ppmw] within the silicon feedstock

\begin{tabular}{cccccc}
\hline $\mathrm{Al}$ & $\mathrm{B}$ & $\mathrm{Ca}$ & $\mathrm{Fe}$ & $\mathrm{Mn}$ & $\mathrm{Cu}$ \\
\hline 3634 & 36 & 13 & 18 & 1 & 2 \\
\hline
\end{tabular}

\section{Materials and methods}

The silicon samples tested in the present work were obtained from a multicrystalline silicon block crystallised using the vertical gradient freeze method [4]. The concentration of impurities encountered in the silicon feedstock was measured using inductively coupled plasma optical emission spectrometry (ICP-OES). The content of different impurities within the silicon feedstock is summarised in Table 1.

\section{Strength measurement}

Silicon wafers with a thickness of approximately $260 \mu \mathrm{m}$ were cut using a multi-wire slurry saw. Wafers from three different positions within the block were collected and etched to remove any sub-surface damage that lowers the mechanical strength of the silicon wafers [5]. Therefore, a silicon layer that was $12-15 \mu \mathrm{m}$ thick was removed from each side of the wafers. The etched multicrystalline silicon wafers were diced with a laser into 49 round chips that were $22 \mathrm{~mm}$ in diameter. These chips were analysed using a ring-on-ring bending test following the specifications in the literature [6]. The diameters of the supporting and loading rings were 18 and $6 \mathrm{~mm}$, respectively. The maximum principle stresses at which the wafers broke during the ring-on-ring bending test were calculated from the measured force-displacement curves using the finite element program ansys.

Additionally, silicon samples with a thickness of $2 \mathrm{~mm}$ were cut using a multi-wire saw. Samples from six different positions within the block were collected, shaped to a sample width of $10 \mathrm{~mm}$ and strongly etched to remove any sub-surface damage and to obtain smooth edges and corners. 20-25 samples were broken using a three-point bending test. The span between the supporting rods was $20 \mathrm{~mm}$. The maximum deflection during bending was considerably smaller than the thickness of the samples. Therefore, the fracture stresses were calculated using the equations from linear-elastic fracture theory [7].

Finally, a two-parameter Weibull distribution was fit to the fracture stress values which were measured either with the ring-on-ring or the three-point bending test, using the maximum likelihood method as reported in the literature [8].

Fracture toughness measurement

Bending tests of precracked specimens is a common procedure to measure the toughness of ceramics. Samples with a thickness of 2 and $10 \mathrm{~mm}$ width were prepared to measure the toughness of the same multicrystalline silicon samples that were broken with the three-point bending test. Therefore, the fracture toughness was measured at six positions within the silicon block. A notch was introduced onto one side of the samples straight-through and perpendicular to the surface of the samples using a steel diamond wire with a diameter of $130 \mu \mathrm{m}$. The length of the notches was measured at five different positions, and the medium value was considered as the notch length. The samples were broken using a three-point bending test where the notch in the sample was carefully aligned with the central loading rod. The span between the supporting rods was $10 \mathrm{~mm}$. Guinea et al. [9] proposed a simple and general expression for calculating the stress intensity factors from the values of the maximum load and the length of the notches for this type of test.

Dynamic elastic modulus measurement

Elastic materials exhibit specific mechanical resonant frequencies that are determined by the elastic modulus, mass and geometry of the test specimens [10] and [11]. Therefore, the macroscopic elastic moduli of the samples were measured before performing the bending tests. The mass and exact dimensions of the samples were measured. The samples were placed onto two anti-vibration supports, and the vibration of the sample was excited by exerting an impulse on the middle of the length of the beam. The resonant frequency of the sample beam was measured using a piezoelectric sensor, which was in contact with the sample, and recorded on the display of an oscilloscope connected to the sensor. Given the mass, dimensions and mechanical resonant frequency of the samples, their elastic moduli were calculated as indicated in the literature [11]

\section{Microstructure analysis}

Impurity inclusions were observed at different block heights with the scanning electron microscope (SEM) and with infrared light microscopy. Additionally, the chemical composition of these inclusions was qualitatively examined with energy dispersive X-ray spectroscopy (EDX).

\section{Theory}

Mechanical strength

Silicon is brittle at room temperature, and it therefore exhibits a linear-elastic mechanical behaviour that is typical of ceramics. The mechanical strength of ceramics is sensitive to defects. The most detrimental type of defect is 
usually micro-cracks, where stresses intensify at the tip of the cracks. When the stress intensity factor of a crack loaded under mode I [3] and [12] reaches a critical value, which is called the 'critical stress intensity factor' or 'fracture toughness', the crack propagates in the material:

$K_{\mathrm{Ic}}=Y \sigma \sqrt{a}$,

where $Y$ is a geometrical factor, $\sigma$ is the stress at the tip of the crack and $a$ is the length of the crack.

Pores or voids and inclusions are usually the second and the third most important causes of fracture, respectively [3]. Directionally solidified silicon does not significantly present pores within the silicon matrix. Therefore, inclusion impurities remain the most relevant type of defect, which influence the mechanical strength of multicrystalline silicon wafers after removing the micro-cracks introduced during the multi-wire sawing of the silicon wafers.

\section{Thermal mismatch}

Thermal residual stress Residual thermal stress is a type of stress that remains in the silicon matrix after the crystallisation process. This stress is caused during the cooling of the multicrystalline silicon blocks by the difference in the thermal expansion coefficients between the silicon matrix and the inclusion impurities. Thermal stresses accumulate around spherical inclusion impurities in the radial and tangential directions, and they are given by [13] and [14]

$\sigma_{r r}=-P\left(\frac{R}{r}\right)^{3}$

$\sigma_{\theta \theta}=\frac{P}{2}\left(\frac{R}{r}\right)^{3}$

$P=\frac{\left(\alpha_{i}-\alpha_{\mathrm{Si}}\right)\left(T_{\mathrm{f}}-T\right)}{\frac{\left(1+v_{\mathrm{Si}}\right)}{2 E_{\mathrm{Si}}}+\frac{\left(1-2 v_{i}\right)}{E_{i}}}$,

where $\alpha_{\mathrm{Si}, i}, v_{\mathrm{Si}, i}$ and $E_{\mathrm{Si}, i}$ are the expansion coefficients, Poisson's ratio and elastic modulus for silicon and the inclusion, respectively. $P$ is the stress inside the inclusion, and $T_{\mathrm{f}}$ is the ductile-brittle transition temperature in silicon ( $775^{\circ} \mathrm{C}$ ) [15]. Above $T_{\mathrm{f}}$, silicon can accommodate stresses through the creation and movement of dislocations in the silicon matrix. However, below $T_{\mathrm{f}}$, the silicon matrix cannot relax the thermal stresses and residual stresses accumulate in the silicon matrix. $T$ is the ambient temperature, $R$ is the inclusion radius and $r$ is the distance from the centre of the inclusion. If the thermal expansion coefficient of the inclusion impurity is less than that of silicon, tangential thermal stresses, $\sigma_{\theta \theta}$, are tensile in nature, and radial micro-cracking can occur. However, when the thermal expansion coefficient of the inclusion impurity is greater than that of silicon, radial thermal stresses, $\sigma_{\mathrm{rr}}$, are tensile in nature, and circumferential micro-cracking can occur [12].

Spontaneous micro-cracking In early experiments, it was observed that micro-cracking after cooling occurs only in the surroundings of inclusions larger than a critical inclusion size. Davidge et al. [16] proposed a criterion for circumferential micro-cracking based on the existence of a flaw near the inclusion interface. The elastic stored energy in the inclusion and in the surrounding silicon matrix supplies the energy necessary for the interfacial flaw to grow. The total stored elastic energy must equal or exceed the energy necessary to create a new fracture surface. The critical inclusion radius for circumferential micro-cracking can be calculated as follows [16]:

$R_{\mathrm{c}} \geq \frac{8 \gamma_{\mathrm{Si}}}{P^{2}\left[\frac{\left(1+v_{\mathrm{Si}}\right)}{E_{\mathrm{Si}}}+\frac{2\left(1-2 v_{i}\right)}{E_{i}}\right]}$

where $\gamma_{S i}$ is the fracture surface energy of silicon.

Ito et al. [17] proposed another model for evaluating circumferential micro-cracking. This model is based on the calculation of the strain energy release rate as a function of the inclusion size and the size of a flaw at the interface of the inclusion. Micro-cracking occurs when the strain energy release rate reaches a critical value at small interfacial flaws:

$R_{\mathrm{c}} \geq 1.79\left(\frac{K_{\mathrm{Ic}}}{\Delta \alpha \Delta T}\right)^{2} \frac{\left[\frac{1+\nu_{\mathrm{Si}}}{2 E_{\mathrm{Si}}}+\frac{1-2 v_{i}}{E_{i}}\right]}{E_{\mathrm{Si}} \sin \varphi(2-\sin \varphi)}$

where $K_{\text {Ic }}$ is the fracture toughness, $a$ is the pre-existing flaw size and $\varphi=a / R$.

Evans et al. [18] proposed spontaneous micro-cracking criteria based on approximations of stress intensity factors at pre-existing defects at or near the interface between a circular inclusion and the silicon matrix. If the stress intensity factor exceeds the value of fracture toughness, $K_{\mathbf{I c}}$, for the matrix at pre-existing flaws, cracks will propagate. The criterion for spontaneous circumferential and radial microcracking is respectively given for an interfacial flaw length of $0.2 R$ by Eqs. (3.7) and (3.8):

$R_{\mathrm{c}} \approx \frac{10}{\pi}\left(\frac{K_{\mathrm{Ic}}}{P}\right)^{2}$,

$R_{\mathrm{c}} \approx \frac{10}{\pi}\left(\frac{40 K_{\mathrm{Ic}}}{11 P}\right)^{2}$

In the case of radial spontaneous micro-cracking, Green [19] proposed a cracking criterion for spherical inclusions with an annular initial flaw. The criterion is based on the calculation of the stress intensity factor of an annular flaw at the equator of the inclusion. In this case, the critical inclusion radius for spontaneous radial micro-cracking is 
Fig. 1 Coordinate system used to evaluate the mechanical stresses around inclusions [18]

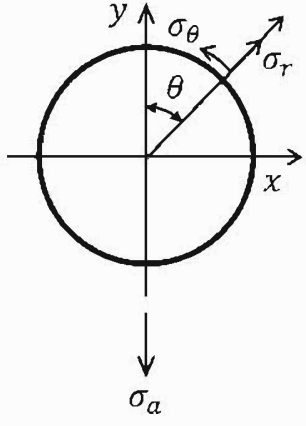

$R_{\mathrm{c}}=\frac{\pi K_{\mathrm{Ic}}^{2}(\varphi+1)^{5}}{\varphi P^{2}(\varphi+2)}$

\section{Elastic mismatch}

Stress intensification can occur in the surroundings of an inclusion when an external load is applied. The difference in elastic constants between silicon and the inclusion impurity is responsible for the disturbance of an applied stress field, $\sigma_{a}$. This elastic stress depends on the angle of orientation, $\theta$, with the applied load (see Fig. 1).

Goodier [20] derived expressions for calculating the stress distribution in the vicinity of a circular inclusion:

$$
\begin{aligned}
\sigma_{r r}= & \frac{\sigma_{a}}{2}(1+\cos 2 \theta) \\
& +2 \sigma_{a}\left[-A\left(\frac{R}{r}\right)^{2}+B\left(\frac{R}{r}\right)^{4}-4\left(\frac{R}{r}\right)^{2}\right] \cos 2 \theta \\
\sigma_{\theta \theta}= & \frac{\sigma_{a}}{2}(1-\cos 2 \theta)+2 \sigma_{a}\left[-A\left(\frac{R}{r}\right)^{2}-3 B\left(\frac{R}{r}\right)^{4} \cos 2 \theta\right] .
\end{aligned}
$$

The terms $A$ and $B$ depend on the elastic constants of the silicon matrix and the impurity inclusion and can be calculated as indicated in the literature [20]. Inclusions with elastic constants lower than those of silicon experience maximum tangential stresses at an orientation of $90^{\circ}$ from the applied load. However, inclusions with elastic constants greater than those of silicon experience maximum radial stresses at an orientation of $0^{\circ}$ from the applied load.

Fracture toughness

The fracture toughness of a ceramic can be influenced by secondary phase inclusions. Khaund et al. and [21] Li et al. [22] analysed the change in the stress intensity factor of a crack approaching a inclusion due to thermal mismatch and due to a uniaxial stress field respectively.

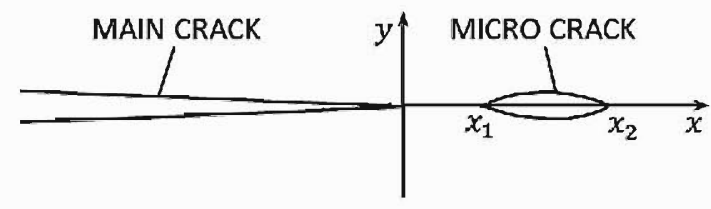

Fig. 2 Two-dimensional configuration of collinear micro-crack ahead of the main crack [24]

Tangential thermal stresses are tensile for inclusions that have thermal expansion coefficients that are less than that of silicon. Therefore, the stress intensity factor that a crack tip experiences when the crack is approaching the inclusion is increased, and the crack is accelerated towards the inclusion. A soft inclusion $\left(E_{i}<E_{\mathrm{Si}}\right)$ amplifies the energy release rate of a crack when it approaches the inclusion; thus, the propagation of the crack is also accelerated. Therefore, if the inclusion has a lower thermal expansion coefficient and lower elastic modulus than the silicon bulk, the crack is attracted to the inclusion, and the toughness of silicon decreases.

Inclusions that have larger thermal expansion coefficients than silicon and thus experience compressive tangential residual thermal stress in their surroundings decrease the local stress intensity factor at the crack tip. The approaching crack is then decelerated. Also, in the case of a stiff inclusion $\left(E_{i}>E_{\mathrm{Si}}\right.$ ), the crack is shielded as it approaches the inclusion, and the crack front is decelerated. Therefore, if the inclusion has a larger thermal expansion coefficient and larger elastic modulus, the toughness of silicon increases [23].

In the case where spontaneous micro-cracking in the vicinity of the inclusions occurs during crystallisation, the toughness of silicon can be diminished. Rose [24] proposed an estimation for the degradation of the fracture toughness due to collinear micro-cracks linking up with the advancing main crack (see Fig. 2).

Elastic modulus

Silicon is an anisotropic crystal; therefore, its elastic constants depend on the orientation of the crystal. Because the calculations in this work are based on the assumptions that the material is continuous, homogeneous and isotropic; a quasi-isotropic approximation of the elastic modulus for multicrystalline silicon will be required as a reference value for our silicon wafers. The elastic modulus can be averaged with the Voigt average method, $E_{V}$, over the elastic constants, $c_{11}, c_{12}, c_{44}$ [25] and with the Reuss average method, $E_{R}$, over the compliances, $s_{11}, s_{12}, s_{44}$ [15]. The Voigt and Reuss moduli are the upper and lower bounds of the elastic modulus, respectively; therefore, the average value of the 
Voigt and Reuss moduli is a good estimate for the quasiisotropic elastic modulus of silicon [3].

It is also observed in the literature that the elastic modulus of ceramics depends on the elastic properties and volume fraction of inclusions. Increasing the volume fraction of stiffer inclusions increases the elastic modulus of the ceramic. Furthermore, increasing the volume fraction of softer inclusions or pores and cracks decreases the elastic modulus of the ceramic. Hashin and Shtrikman [26] determined the bounds for the elastic modulus of a ceramic that contains secondary phase inclusions.

Special attention should be drawn to the decrease in elastic modulus when spontaneous micro-cracking of the silicon matrix occurs after the crystallisation process. Budiansky and O'Connell [27] proposed a model for predicting the elastic constants of an isotropic and homogeneous solid with randomly distributed cracks. According to this model, the decrease in the elastic modulus depends on a crack density parameter.

\section{Microscopic failure criteria}

We will suggest in this section a failure prediction for the different types of impurity inclusions according to the configuration of thermal stresses and intensification of applied stress.

A conservative failure criterion consists of equalling the inclusion size to the critical crack length in the general expression of Eq. (3.1). The inclusion is considered in this case to intensify the stress in its vicinities with the same efficiency as that of a crack. The stress acting on the inclusion is considered to be the addition of the applied intensified load, $\sigma_{\mathrm{a}}$, and thermal residual stress $\sigma_{\text {th }}$. The critical inclusion radius causing failure is then

$R_{\mathrm{c}} \geq\left(\frac{K_{\mathrm{Ic}}}{Y\left(\sigma_{\mathrm{th}}+\sigma_{a}\right)}\right)^{2}$.

Values for the geometry factor can be found in the literature [3] depending on the geometry of the originated cracks and the loading configuration.

Besides a conservative failure criterion, more specific and accurate failure predictions can be formulated analysing the thermal and mechanical stress distributions around the inclusions.

For particles in a silicon matrix with very high thermal expansion coefficients, $\left(\alpha_{\mathrm{p}} \gg \alpha_{\mathrm{Si}}\right)$, circumferential microcracking may most probably be present in the silicon matrix due to the high value of thermal stress [16]. Microcracks represent then the dominant type of defect limiting the strength of the specimen and failure can be predicted using Eq. (3.1).
In the case that spontaneous micro-cracking of the silicon matrix does not occur after directional solidification, cracks can develop due to the overlap of residual thermal stress and applied stress in the surroundings of the inclusions.

Green [19] suggested some expressions to predict critical inclusion size for radial and circumferential microcracking due to an applied stress in the vicinity of a spherical inclusion with a residual thermal stress field in its surroundings. It is assumed that the matrix and the inclusion have the same elastic properties; therefore, Green's analysis is only valid for systems where residual thermal stresses are larger than stresses due to elastic mismatch.

Circumferential micro-cracking occurs when the inclusion has larger thermal expansion coefficients than silicon, and the critical stress intensity factor is reached at an initial flaw of length $a(a=R \varphi)$ at the interface between the inclusion and the silicon matrix. The critical inclusion radius in this case is as follows:

$$
R_{\mathrm{c}} \geq \frac{K_{\mathrm{Ic}}^{2}}{\varphi\left(P\left(\frac{1.68}{1+\nu_{\mathrm{si}}}\right)^{1 / 2}+1.128 \sigma_{a}\right)^{2}} .
$$

Radial micro-cracking is expected when the inclusion has lower thermal expansion coefficient than the matrix. Under this configuration, initial flaws which are perpendicular to the interface are most deleterious. Critical inclusion radius for radial micro-cracking is therefore

$$
R_{\mathrm{c}} \geq \frac{\pi K_{\mathrm{Ic}}^{2}(\varphi+1)^{5}}{\varphi\left(2 \sigma_{a}(\varphi+1)^{2}-P\right)^{2}(\varphi+2)} .
$$

Evans [18] proposed expressions for the stress intensity factors of initial flaws in the vicinity of circular inclusions due to thermal and elastic mismatch. If the addition of the stress intensity factors due to thermal mismatch and an applied load reach the critical stress intensity factor, then failure occurs. If the initial flaw is exactly located at the particle's interface and has a length of $0.2 R$, then the critical inclusion radius for radial cracking of an inclusion with lower expansion coefficient than the one of silicon is

$R_{\mathrm{c}} \geq \frac{10}{\pi}\left(\frac{K_{\mathrm{Ic}}}{\frac{11}{40} P+\sigma_{a}\left(1+\frac{7}{5} A+\frac{48}{5} B\right)}\right)^{2}$.

It has to be mentioned that the study of the fracture surfaces of the broken samples showed that the fracture pattern of silicon is considerably complex. Impurity inclusions or clear fracture initiation features could not be found and measured easily. A reason for this could be that the inclusion or group of inclusions causing failure loosen after fracture. Thus, a proper application of a macroscopic fracture criteria is not presented in this work. Instead, the 
application of the explained microscopic failure criteria is applied for failure prediction.

\section{Results}

Relatively large-sized inclusions were observed within the multicrystalline silicon block throughout the entire length of the block. During crystallisation, aluminium, carbon and nitrogen segregate to the liquid phase and, consequently, to the upper regions of the block. Therefore, the precipitation of $\mathrm{SiC}$ and $\mathrm{Si}_{3} \mathrm{~N}_{4}$ increased from the bottom to the top of the block as the silicon melt experienced a higher concentration of these impurities. The precipitation of $\mathrm{SiC}$ and $\mathrm{Si}_{3} \mathrm{~N}_{4}$ could have been enhanced by the decreased solubility of carbon and nitrogen in the silicon melt, which was caused by the high content of aluminium within the melt. This supposition is supported by experimental evidence since extensive microstructure observation with the SEM revealed a relevant increase in the precipitation of $\mathrm{SiC}$ and $\mathrm{Si}_{3} \mathrm{~N}_{4}$ particles together with the formation of $\mathrm{Al}$ rich inclusions at the same block height (see Figs. 3, 4, 5). Circumferential or radial micro-cracking was not observed with the electron scanning microscope in the surroundings of the $\mathrm{SiC}$ and $\mathrm{Si}_{3} \mathrm{~N}_{4}$ inclusions (see Figs. 3, 4), which appear well bonded to the silicon matrix.

Aluminium segregated to the upper part of the block, and aluminium-rich inclusions began to precipitate at approximately $60 \%$ of the relative block height (see Fig. 5). Micro-cracks in the range of several tens of microns were observed in the surroundings of and within these aluminium-rich inclusions.

The concentration of aluminium in the remaining silicon melt at the end of the crystallization process reached the eutectic concentration for the silicon-aluminium system at

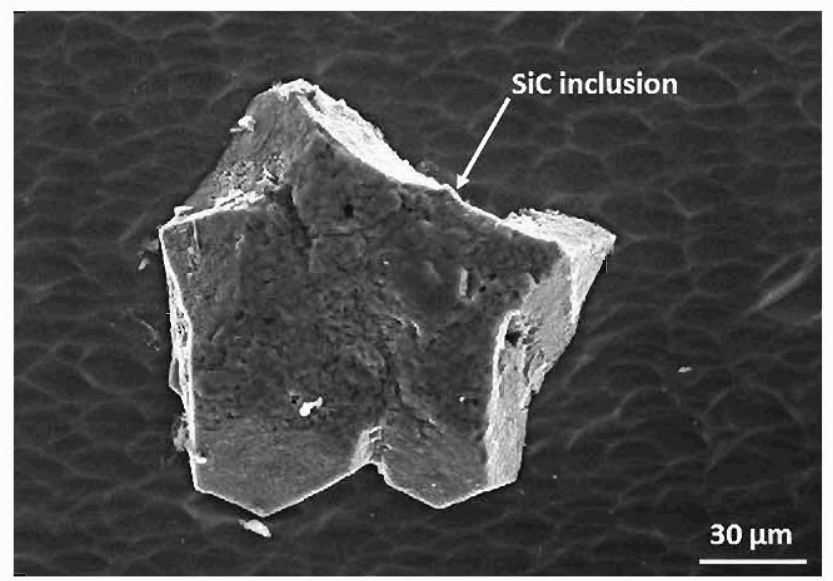

Fig. $3 \mathrm{SiC}$ inclusion in the silicon matrix at $63 \%$ of the relative block height

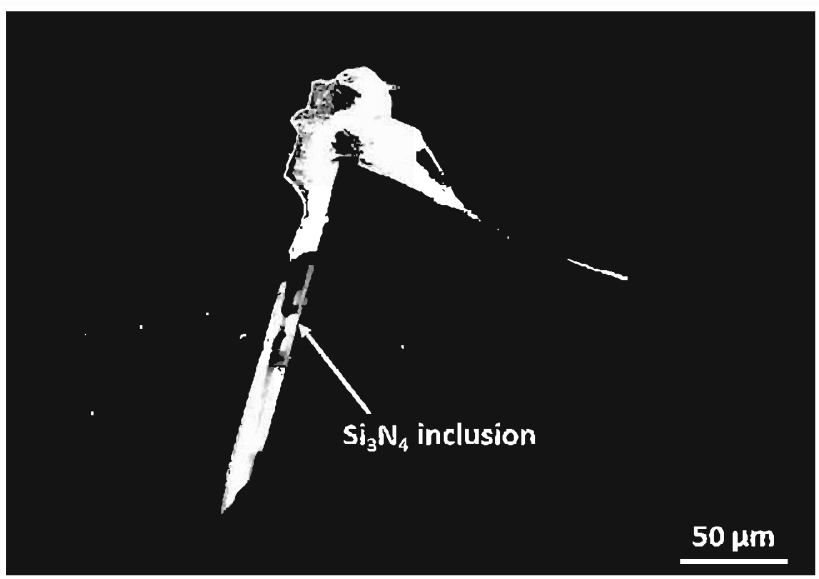

Fig. $4 \mathrm{Si}_{3} \mathrm{~N}_{4}$ inclusion in the silicon matrix at $63 \%$ of the relative block height

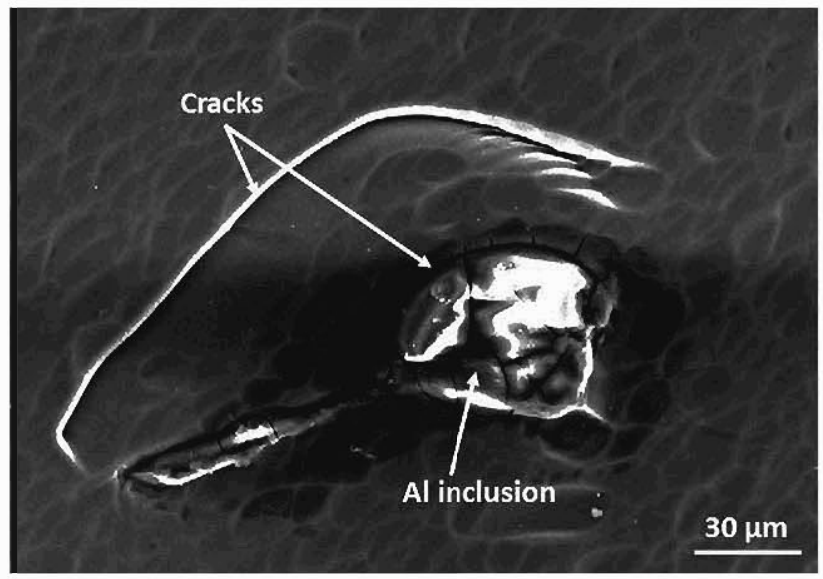

Fig. 5 Micro-cracks formed in the surroundings of an aluminiumrich inclusion at $63 \%$ of the relative block height

approximately $70 \%$ of the relative block height. Therefore, an aluminium eutectic phase precipitated (see Fig. 6a) with long micro-cracks in its surroundings that reached lengths of up to $1 \mathrm{~mm}$. The EDX map depicted in Fig. 6b illustrates the chemical composition of this phase which speaks for the eutectic precipitation of the Al phase.

The results show the tendency of the mechanical strength, fracture toughness and elastic modulus against the relative block height. Both mechanical strengths, measured with the ring-on-ring and three-point bending tests (see Fig. 7), decrease from the bottom to the top of the multicrystalline silicon block. The mechanical strength decreases until $60 \%$ of the relative block height as the density and size of the $\mathrm{SiC}$ and $\mathrm{Si}_{3} \mathrm{~N}_{4}$ inclusions increase. The fracture toughness of the silicon samples experiences an inverse tendency and slightly increases with the increasing precipitation of $\mathrm{SiC}$ and $\mathrm{Si}_{3} \mathrm{~N}_{4}$ inclusions (see Fig. 8). The elastic 

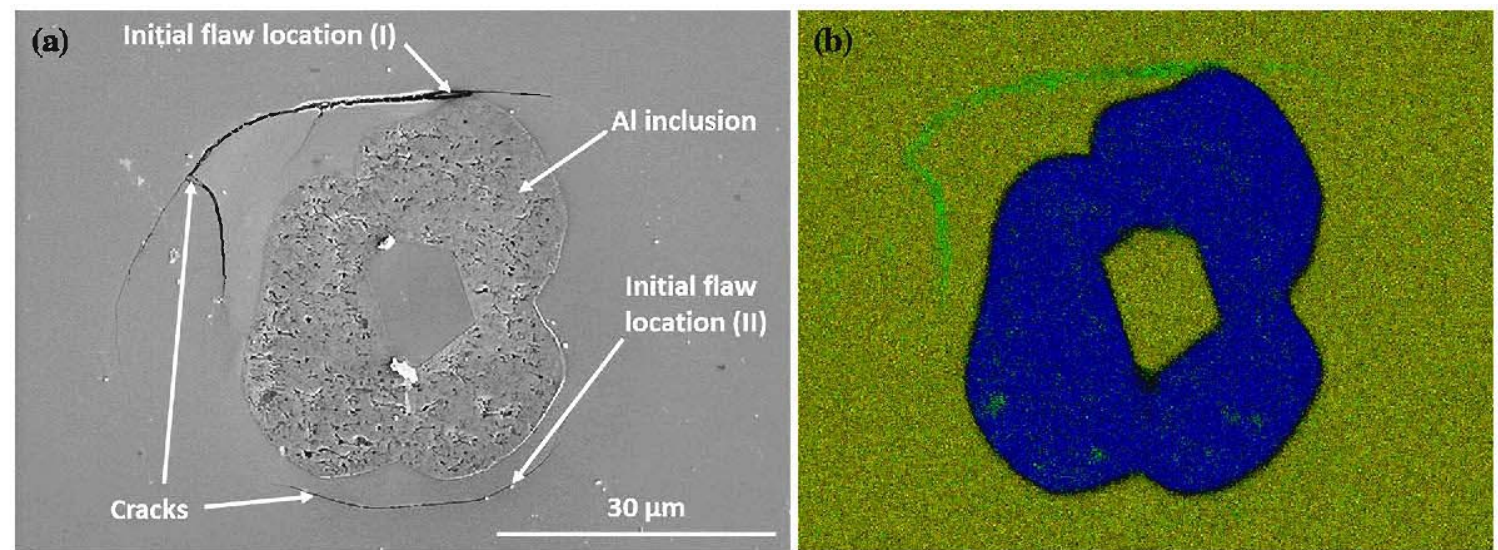

Fig. 6 Image a shows micro-cracks formed in the surroundings of a eutectic aluminium phase at $77 \%$ of the relative block height. Image b illustrates an EDX map of the $\mathrm{Al}$ eutectic phase depicted in image a where the yellow colour states for $\mathrm{Si}$, blue for $\mathrm{Al}$ and green for $\mathrm{O}$

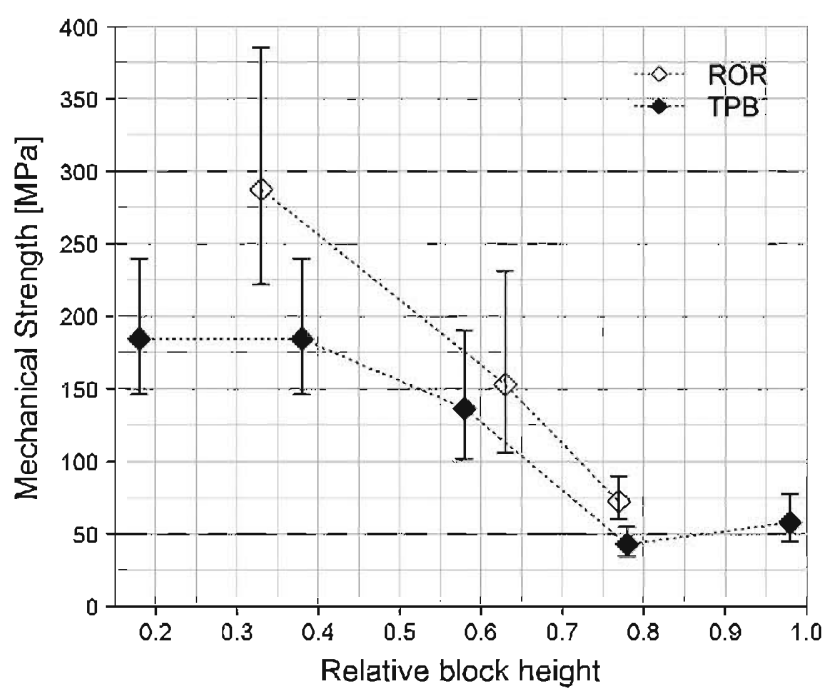

Fig. 7 Mechanical strength against relative block height. The points indicate the Weibull characteristic stress, and the error bars indicate their corresponding upper and lower $90 \%$ confidence intervals. ROR and TPB state for ring-on-ring and three-point bending test respectively

modulus is slightly greater than the average elastic modulus of silicon $(162.6 \mathrm{MPa})$ in the parts of the block where $\mathrm{SiC}$ and $\mathrm{Si}_{3} \mathrm{~N}_{4}$ inclusions are encountered (see Fig. 9).

Because aluminium inclusions form in the silicon matrix within the upper parts of the block, all of the mechanical properties considerably decrease. This result is most likely due to the formation of very long cracks in the surroundings of the aluminium phases. The amount of aluminium phase is maximum between 70 and $80 \%$ of the relative block height, which is where the mechanical properties of this type of multicrystalline silicon reach their minimum values.

The measured values for the Weibull modulus, reporting the widths of the distribution length of the defects

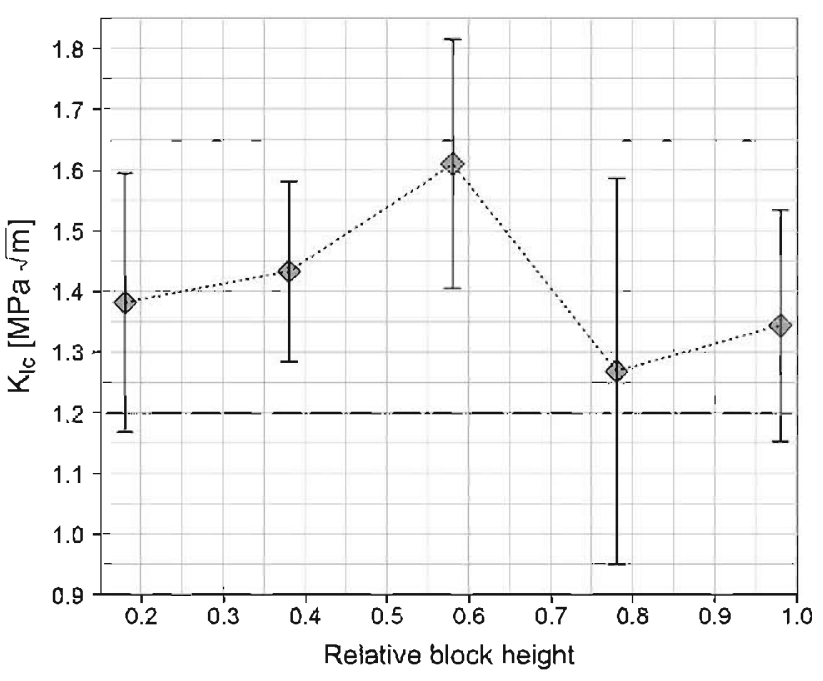

Fig. 8 Fracture toughness against relative block height. The error bars indicate the standard deviation of the measurements

contained in the tested silicon samples that controlled their mechanical strengths, are not reported in this work. The reason is that these values of the Weibull modulus did not show any clear tendency against the relative block height. The Weibull modulus values remained relatively low and constant for all groups of samples, ranging these values and their $90 \%$ confidence intervals between 2 and 7 . The conclusion that could be extracted from the Weibull modulus values is that all groups of samples showed comparable widths of defects length distribution.

\section{Discussion}

In this section, the experimental results are contrasted with the theoretical models for the mechanical behaviour 


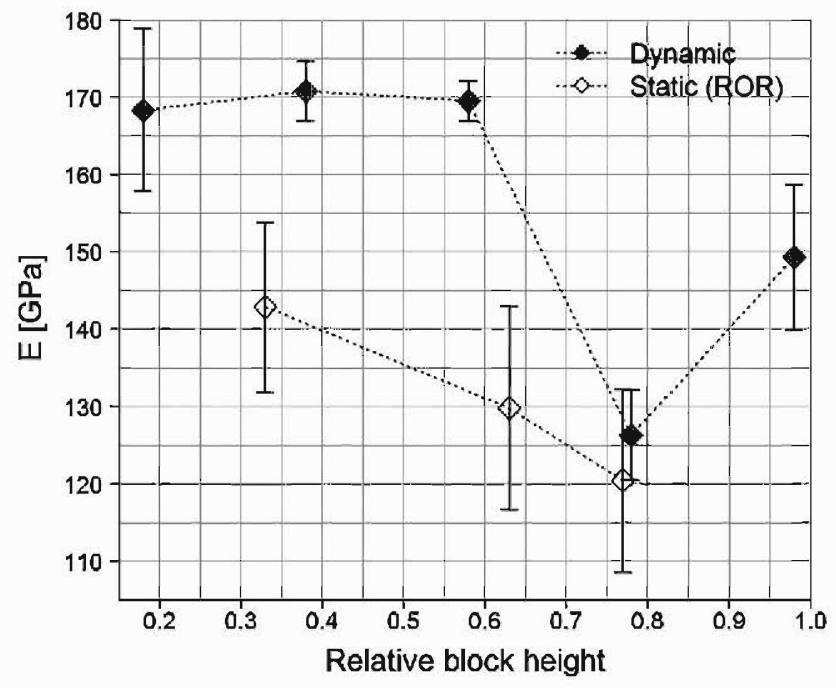

Fig. 9 Macroscopic elastic modulus against relative block height. The error bars indicate the standard deviation of the measurements

Table 2 Material properties for silicon and the impurities found within the crystallised block

\begin{tabular}{lllll}
\hline Material & $\alpha \times 10^{6}\left(\mathrm{~K}^{1}\right)$ & $\nu(-)$ & $E(\mathrm{GPa})$ & $K_{\text {Ic }}(\mathrm{MPa})$ \\
\hline $\mathrm{Si}$ & 4.3 & 0.218 & 162.6 & $0.83-0.94$ \\
$\mathrm{Al}$ & 23 & 0.34 & 69 & $22-30$ \\
$\mathrm{Si}_{3} \mathrm{~N}_{4}$ & 2.35 & 0.27 & 310 & $4-6$ \\
$\mathrm{SiC}$ & 4.8 & 0.15 & 380 & $2.5-5$ \\
\hline
\end{tabular}

of ceramics to evaluate the causes of breakage and to predict the fracture stresses of silicon containing different inclusion impurities. Table 2 presents the material parameters used for calculating thermal residual stresses, critical inclusion radius, elastic stresses, change in local toughness, elastic modulus and fracture criteria.

The thermal expansion coefficients of silicon, silicon carbide and silicon nitride are temperature dependent [28-30]. Therefore, the values for these materials shown in Table 2 are taken at $775{ }^{\circ} \mathrm{C}$, which is the brittleductile temperature of silicon considered in this work [15]. The elastic modulus and Poisson's ratio of silicon carbide and silicon nitride at $775^{\circ} \mathrm{C}$ were published by Sakaguchi et al. [31]. The remainder of the properties is taken from [32]. Sinclair and Lawn [33] estimated the surface energies of different crack planes for crystals that adopt the diamond structure. In the case of silicon, the surface energy values of the $\{111\}$ and $\{110\}$ planes are 1.41 and $1.74 \mathrm{~J} \mathrm{~m}^{-2}$, respectively. Therefore, the mean value of $1.6 \mathrm{~J} \mathrm{~m}^{-2}$ is used for the calculations in this work.

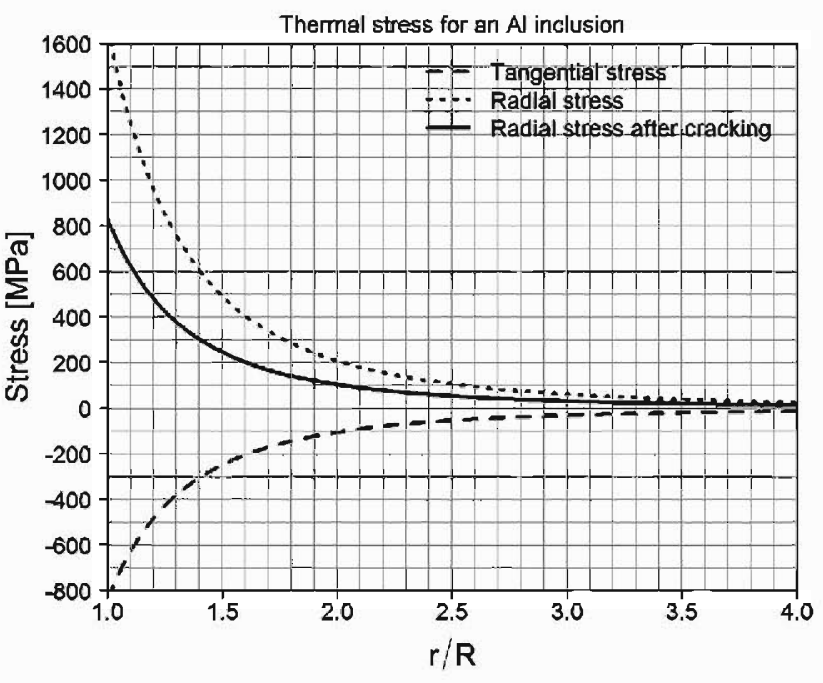

Fig. 10 Radial and tangential residual thermal stress profiles in the surroundings of an aluminium inclusion according to Eqs. 3.2 and 3.3

\section{Aluminium}

The results in the previous section revealed a decrease in all of the mechanical properties at the upper part of the multicrystalline silicon block where metal impurities can segregate. The thermal mismatch between aluminium and silicon is critical due to the large difference in their thermal expansion coefficients (see Table 2). Aluminium can accumulate thermal stresses in the radial direction up to $1,600 \mathrm{MPa}$ at the interface of the inclusion (see Fig. 10).

These large residual thermal stresses reveal that the critical inclusion size for circumferential micro-cracking in the case of aluminium is small. The model of Davidge (Eq. 3.5) presents a conservative estimate for the critical inclusion size. In the case of aluminium inclusions within the silicon matrix, this value is less than $1 \mu \mathrm{m}$ (see Table 3). According to Ito et al. (Eq. 3.6), the minimum critical inclusion size is also less than $1 \mu \mathrm{m}$ for aluminium spherical inclusions with initial flaws at the inclusion interface that extend $60-120^{\circ}$. If the inclusion impurity is considered to exhibit a circular form, the critical inclusion radius is, according to Evans (Eq. 3.7), approximately $1 \mu \mathrm{m}$, if an initial flaw size length of $0.2 R$ is assumed. This agreement on the critical inclusion size by the application of different models assures the micro-cracking in the surroundings of aluminium inclusions of such sizes. Semispherical cracks around the inclusions are observed with the SEM (see Figs. 5, 6). This observation is in agreement with the literature [16], and the thermal residual stress reduces to half of its value after micro-cracking.

Figure 11 depicts the decrease in the elastic modulus with increasing crack density in the silicon matrix. The 
Table 3 Critical inclusion size for aluminium, silicon nitride and silicon carbide inclusions within a silicon matrix

\begin{tabular}{lllll}
\hline Inclusion & Davidge $(\mu \mathrm{m})$ & Ito $(\mu \mathrm{m})$ & Green $(\mu \mathrm{m})$ & Evans $(\mu \mathrm{m})$ \\
\hline $\mathrm{Al}$ & 0.27 & 0.39 & - & 0.96 \\
$\mathrm{Si}_{3} \mathrm{~N}_{4}$ & - & - & 175 & 436 \\
$\mathrm{SiC}$ & 252 & 351 & - & 563 \\
\hline
\end{tabular}

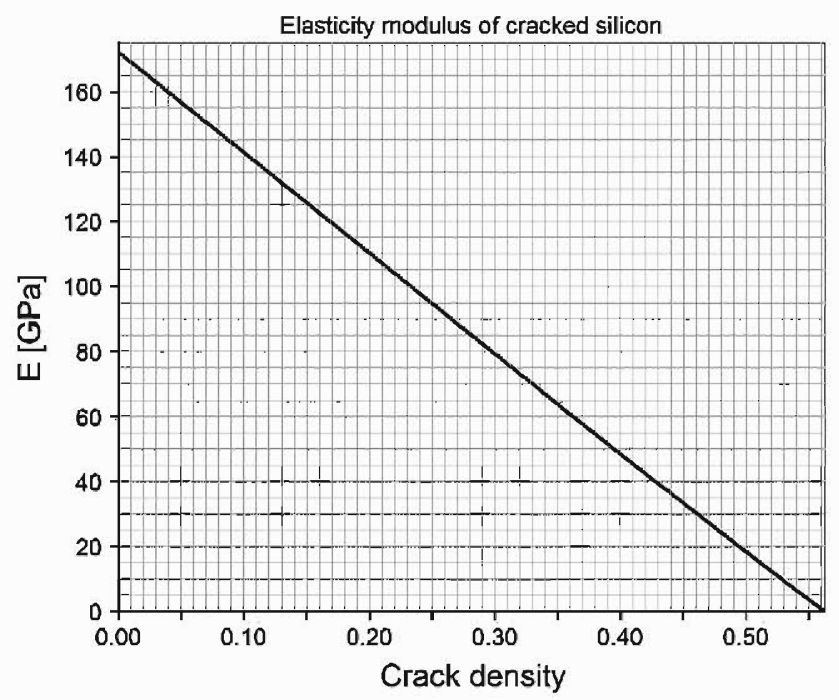

Fig. 11 Decrease in the elastic modulus with increasing density of cracks within the silicon matrix in the case of circular cracks after Budiansky and O'Connell [27]

value of the elastic modulus without micro-cracking is considered to be $\sim 170 \mathrm{GPa}$, which is the mean value of the elastic modulus measured before micro-cracking occurred (see Fig. 9).

Given that the decrease in the elastic modulus measured at $78 \%$ of the relative block height of the multicrystalline silicon (see Fig. 9) was due to micro-cracking, the crack density in silicon can be determined from the graph in Fig. 11. Therefore, a measured elastic modulus of $126 \mathrm{GPa}$ at $78 \%$ of the relative block height corresponds to a crack density value of 0.15 . The decrease in the elastic modulus of silicon also manifests as a decrease of the fracture toughness. According to the calculation proposed by Rose [24], the fracture toughness of cracked silicon with an elastic modulus value of $126 \mathrm{GPa}$ should decrease by $14 \%$. Before micro-cracking occurred, the fracture toughness measured at $58 \%$ of the relative block height was $1.61 \mathrm{MPa} \sqrt{\mathrm{m}}$ (see Fig. 8), and a decrease of $14 \%$ corresponds to a fracture toughness value of $1.39 \mathrm{MPa} \sqrt{\mathrm{m}}$. This value is close to the measured value of $1.26 \mathrm{MPa} \sqrt{\mathrm{m}}$ at $78 \%$ of the relative block height, which is a good approximation but not completely accurate. The inaccuracy could be due to the fact that real values of the elastic modulus and toughness of the material without microcracking at $78 \%$ of the relative block height are not known; therefore, the values of the elastic modulus and toughness of a lower position in the block are considered. The inaccuracy could be also due to the large error bars of the elastic modulus and fracture toughness measurements, which indicates that the material has a relatively inhomogeneous microstructure. Another reason for the inaccuracy could be an underestimation of the decrease in the elastic modulus. Aluminium inclusions cause also a reduction of the elastic modulus of silicon, in addition to micro-cracking, according to Hashin and Shtrikman [26].

Note that the error bars of the fracture toughness measurements are large, and consequently, the observed trend of fracture toughness through the block height must be analysed carefully. Large error bars indicate that the material is significantly inhomogeneous within the same block height. The fracture toughness values measured at $78 \%$ of the relative block height range from $0.95 \mathrm{MPa} \sqrt{\mathrm{m}}$ to $1.58 \mathrm{MPa} \sqrt{\mathrm{m}}$. This result indicates that the tested samples that showed the highest value of $1.58 \mathrm{MPa} \sqrt{\mathrm{m}}$ experienced no to very little crack linking, whereas the samples with very low toughness most likely experienced strong crack linking. The lengths of the notches introduced in the samples for toughness measurements ranged from 0.2 to $0.9 \mathrm{~mm}$. The stress intensity factor required for crack linking is less than the toughness of the material when a propagating crack finds a collinear crack located at a distance smaller than the length of the propagating crack [24]. Therefore, a $0.5 \mathrm{~mm}$ notch senses and links the cracks that may be observed within a distance of $0.5 \mathrm{~mm}$ ahead of its tip. If we consider that the toughness without microcracking at $78 \%$ of the block height is $1.61 \mathrm{MPa} \sqrt{\mathrm{m}}$, then the sample with a measured toughness of $0.95 \mathrm{MPa} \sqrt{\mathrm{m}}$ represents a decrease of toughness to $59 \%$ of the toughness without micro-cracking. If we read the abscissas value for 0.59 in Fig. 12, we can interpret that the notch of this sample linked with a crack located at distance $\sim 7 \%$ of its length.

The fracture criterion when micro-cracking around inclusions occurs is defined by Eq. (3.1). At $78 \%$ of the relative block height, the failure criterion for the threepoint bending test stays as follows:

$$
1.26=Y \times 43.1 \sqrt{\pi a}
$$

where 1.26 is the measured fracture toughness of the material at $78 \%$ of the block height in $\mathrm{MPa} \sqrt{\mathrm{m}}, 43.1$ is the measured characteristic stress in $\mathrm{MPa}$, and $a$ is the length of the crack. The crack length is thus $633 \mu \mathrm{m}$ if the cracks causing failure are considered half-penny-shaped surface cracks under uniaxial load $(Y=2.06 / \sqrt{\pi})$ [3], which is in 


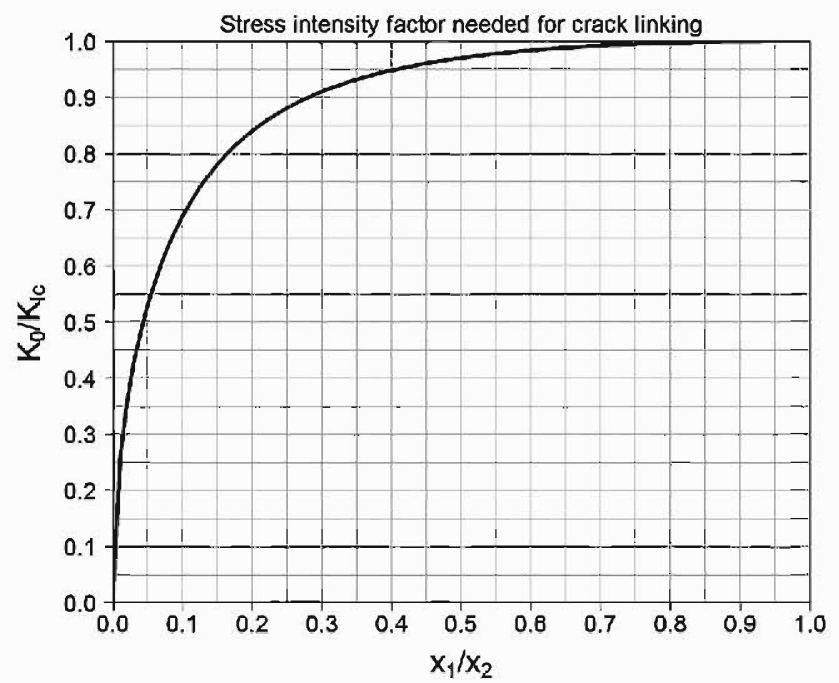

Fig. 12 Decrease in the stress intensity factor at the tip of a crack approaching a collinear crack after Rose [24]. The magnitudes $x_{1}$ and $x_{2}$ are described in Fig. 2

good agreement with the cracks sizes observed under the microscope.

\section{Silicon nitride}

The density of $\mathrm{Si}_{3} \mathrm{~N}_{4}$ and $\mathrm{SiC}$ inclusions increased from the bottom to the top of the block due to the segregation of nitrogen and carbon to the upper part of the block and could be observed with the SEM. A decrease in the mechanical strength measured with the three-point bending test was observed in the first half of the multicrystalline silicon block.

If the $\mathrm{Si}_{3} \mathrm{~N}_{4}$ particle is considered to be spherical with an annular initial flaw in its equator (Eq. 3.9), the minimum critical particle radius is $175 \mu \mathrm{m}$ (see Table 3 ) for an initial flaw length of $\sim 0.3 R$. If the $\mathrm{Si}_{3} \mathrm{~N}_{4}$ particle is considered to be circular with an initial flaw size length of $0.2 R$ and perpendicular to the particle's interface (Eq. 3.8), the critical particle radius is $436 \mu \mathrm{m}$. The observed particle sizes were smaller than these two hypothetical cases; therefore, radial micro-cracking of the silicon matrix does not occur in the surroundings of the $\mathrm{Si}_{3} \mathrm{~N}_{4}$ particles after the crystallisation process.

Calculations of thermal stresses for silicon carbide and silicon nitride inclusions within a silicon matrix have been performed in the literature [34], [35]. The overlap of radial and tangential thermal and elastic stresses calculated in this work is depicted in Figs. 13 and 14. The intensification of radial elastic stresses is maximum at an orientation $0^{\circ}$ and $180^{\circ}$ from the applied load but as the magnitude of the radial compressive thermal stresses is larger, a silicon

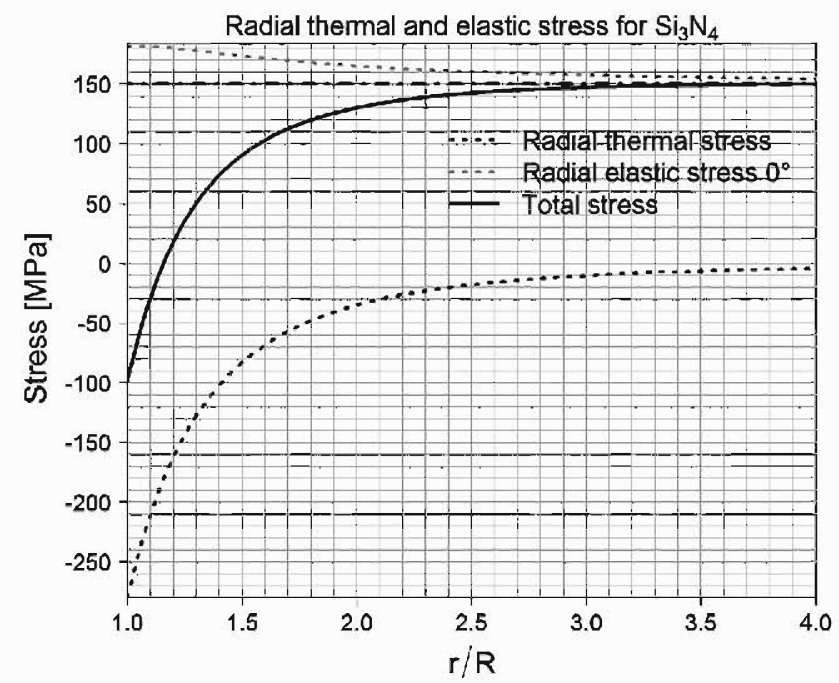

Fig. 13 Profiles of radial thermal stress (Eq. 3.2) and intensification of stress for an applied load of $150 \mathrm{MPa}$ (Eq. 3.10) in the case of a $\mathrm{Si}_{3} \mathrm{~N}_{4}$ inclusion

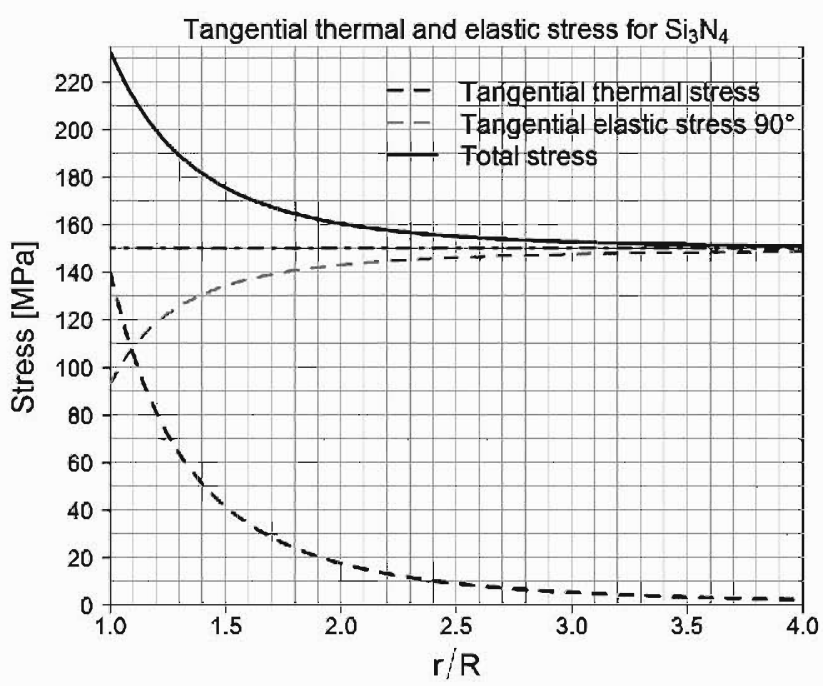

Fig. 14 Profiles of tangential thermal stress (Eq. 3.3) and intensification of stress for an applied load of $150 \mathrm{MPa}$ (Eq. 3.11) in the case of $\mathrm{a} \mathrm{Si}_{3} \mathrm{~N}_{4}$ inclusion

nitride inclusion remains under compression in its vicinities for the given orientation (see Fig. 13). The overlap of tangential elastic stresses with tensile tangential thermal stress reaches a value of $\sim 220 \mathrm{MPa}$ at the inclusion interface for the given orientation (see Fig. 14) when only $150 \mathrm{MPa}$ is applied. The latter is the most critical configuration of overlap of thermal and elastic stresses that can cause failure in the surroundings of a silicon nitride inclusion (see Fig. 15). 


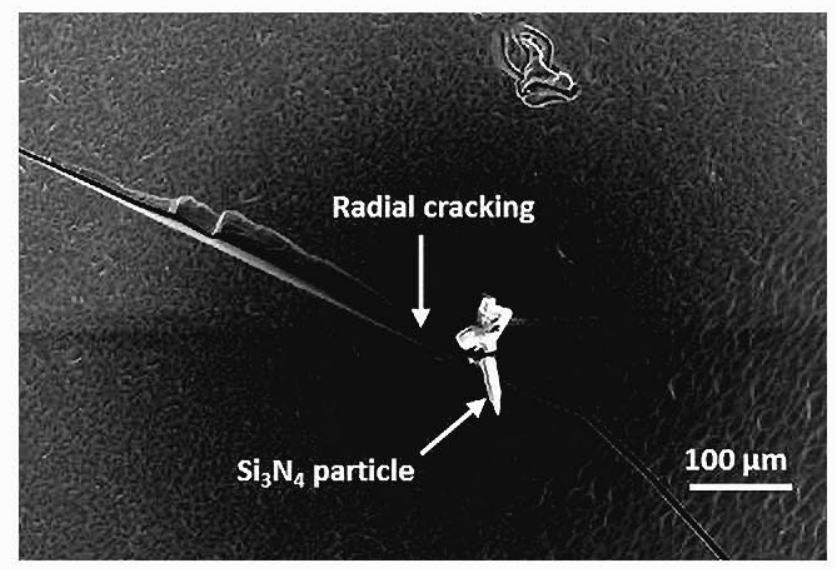

Fig. 15 Front section of fracture at a silicon nitride inclusion

The calculated characteristic stress at $58 \%$ of the block height, which was broken with the three-point bending test, is considered here for microscopic failure prediction because a relevant amount of silicon nitride inclusions was observed at this block height. The measured characteristic stress is $136.8 \mathrm{MPa}$. If the abscissas value for the characteristic stress is read in Fig. 16, the critical inclusion radius for silicon nitride can be obtained. The Green (Eq. 3.14) and Evans (Eq. 3.15) criteria for radial cracking predict a critical inclusion size of 32 and $74 \mu \mathrm{m}$, respectively. The conservative failure criterion (Eq. 3.12) predicts a smaller critical inclusion size of $5 \mu \mathrm{m}$. Silicon nitride inclusions do not appear with spherical forms, but they do appear with angular forms. The consideration of a spherical inclusion by Green's model can underestimate the concentration of stress at the corners of the inclusion. A conservative solution for this issue is to consider stress intensification at initial flaws at the inclusion interface. Initial flaws sizes of $0.2 R$ are considered for both the Green and the Evans criteria. These two failure criteria provide a better approximation than the conservative failure criterion for the critical inclusion size that causes radial cracking. The difficulty in determining the faluire criterion that is most suitable for silicon nitride inclusions lies in the determination of the inclusions size by microscope observation and comparison with the inclusion sizes calculated by different models. For the purpose of this work, we choose the Green failure criterion, which is more conservative than the Evans criterion.

A propagating crack needs to release approximately twice the energy for its propagation when it reaches a silicon nitride inclusion interface because silicon nitride is stiffer than silicon [22]. Therefore, according to $\mathrm{Li}$ et al. [22] and for plane stress, the critical stress intensity factor

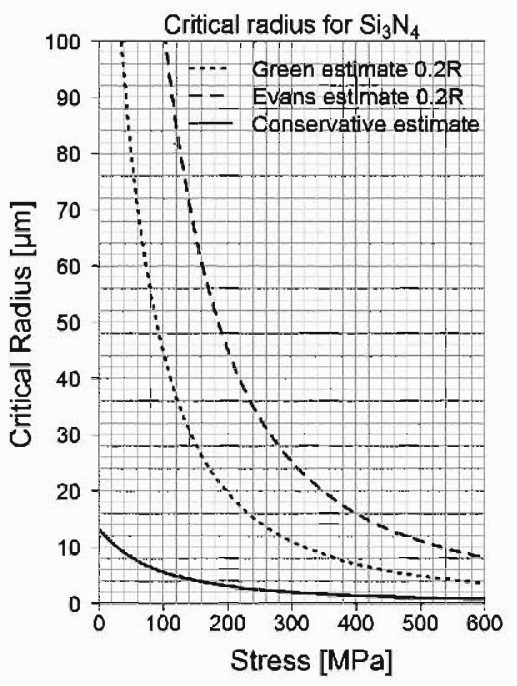

Fig. 16 Critical inclusion radius of silicon nitride inclusions when an external load is applied

of silicon increases from $0.9 \mathrm{MPa} \sqrt{\mathrm{m}}$ to $1.27 \mathrm{MPa} \sqrt{\mathrm{m}}$ in the presence of silicon nitride inclusions. Tensile tangential thermal stresses at the interface of an inclusion with a radius of $30 \mu \mathrm{m}$ already provide $0.72 \mathrm{MPa} \sqrt{\mathrm{m}}$ for crack propagation according to Khaund et al. [21]. Therefore, the application of a uniaxial load that adds $0.55 \mathrm{MPa} \sqrt{\mathrm{m}}$ would cause cracking through the silicon nitride inclusion. This value is still less than the $0.9 \mathrm{MPa} \sqrt{\mathrm{m}}$ required for crack propagation in silicon without inclusions; therefore, the local fracture toughness of silicon diminishes. This analysis concludes that silicon nitride inclusions may not be responsible for the light increase in toughness within the first half of the multicrystalline silicon block. This issue will be discussed further in the following section.

According to Hashin and Shtrikman [26], the presence of silicon nitride in the silicon matrix would increase the elastic modulus of silicon. The results depicted in Fig. 9 show higher elastic modulus values than the average elastic modulus within the first half of the multicrystalline silicon block where silicon nitride inclusions are observed.

\section{Silicon carbide}

The density of silicon carbide inclusions increased from the bottom to the top of the block due to the segregation of carbon to the upper part of the block.

The values of critical inclusion radius for spontaneous micro-cracking of SiC are shown in Table 3. The observed inclusion sizes were smaller than the calculated critical 


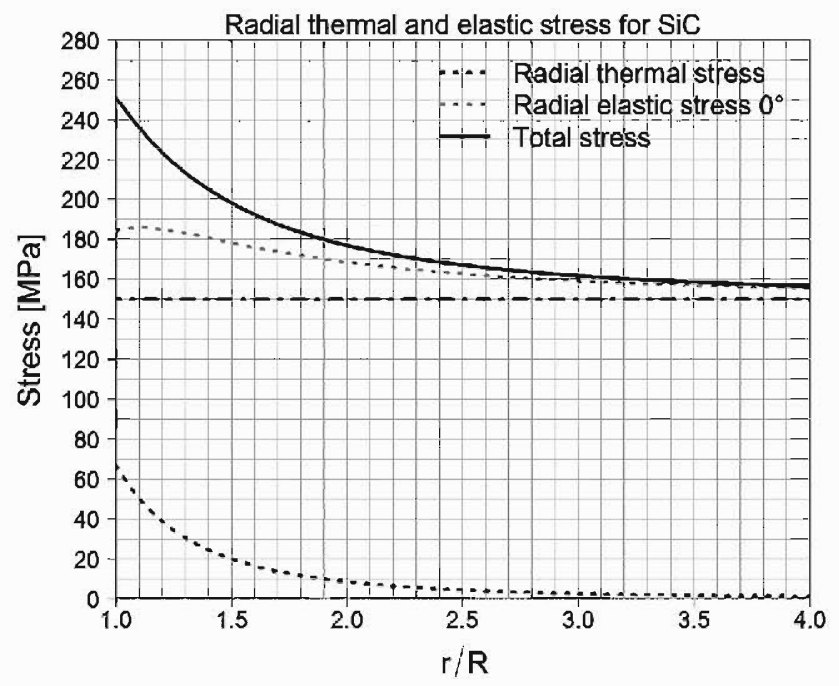

Fig. 17 Overlap of radial thermal (Eq. 3.2) and elastic stresses (Eq. 3.10) in the surroundings of a silicon carbide inclusion

radius, and consequently, micro-cracking of the silicon matrix does not occur in the surroundings of the silicon carbide inclusions.

The maximum overlap of tensile radial thermal and elastic stresses occurs at an orientation of $0^{\circ}$ and $180^{\circ}$ from the applied load and is depicted in Fig. 17. In the case where $150 \mathrm{MPa}$ is applied in the vicinities of silicon carbide, the inclusion would experience $250 \mathrm{MPa}$ at its interface due to the overlap of radial stresses.

If the abscissas value for the measured characteristic stress, $136.8 \mathrm{MPa}$, is read in Fig. 18, the critical inclusion radius for silicon carbide can be obtained. The Green criterion (Eq. 3.13) for circumferential cracking predicts critical inclusion radii of 74 and $38 \mu \mathrm{m}$ for initial interfacial flaws that extend $18^{\circ}$ and $70^{\circ}$, respectively. The conservative failure criterion predicts a smaller critical inclusion size of $4 \mu \mathrm{m}$. The Green failure criterion provides a better approximation than the conservative failure criterion for the prediction of the critical inclusion size that causes cracking (notice the $\mathrm{SiC}$ inclusion size depicted in Fig. 3).

According to Li et al. [22], the propagating crack needs to release approximately twice the energy for its propagation when it reaches the inclusion interface because silicon carbide is stiffer than silicon. Like in the case of silicon nitride, the critical stress intensity factor of silicon increases from $0.9 \mathrm{MPa} \sqrt{\mathrm{m}}$ to $1.27 \mathrm{MPa} \sqrt{\mathrm{m}}$ in the surroundings of a silicon carbide inclusion. Compressive tangential stresses at the interface of a $\mathrm{SiC}$ inclusion with a radius of $30 \mu \mathrm{m}$ increase the toughness by $0.17 \mathrm{MPa} \sqrt{\mathrm{m}}$ according to the model of Khaund et al. [21]. Therefore, crack propagation requires the application of a uniaxial

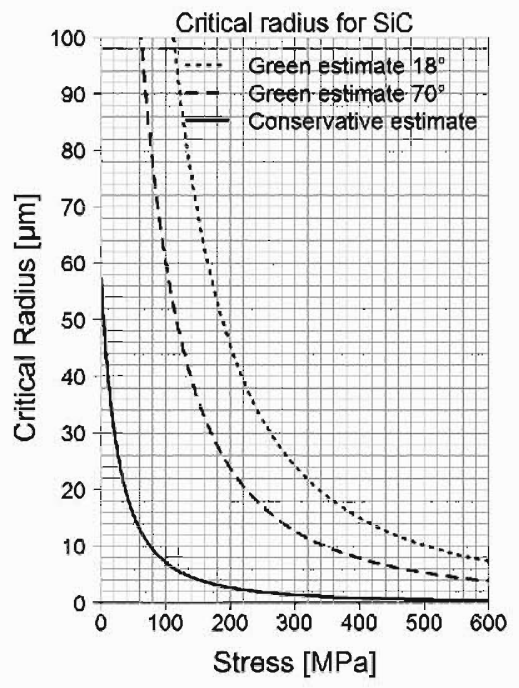

Fig. 18 Critical inclusion radius of silicon carbide when an external load is applied

load that induces $1.44 \mathrm{MPa} \sqrt{\mathrm{m}}$. This value is higher than the $0.9 \mathrm{MPa} \sqrt{\mathrm{m}}$ required for crack propagation in silicon; therefore, the toughness of silicon is increased. This analysis concludes that silicon carbide, not silicon nitride, inclusions may be responsible for the total increase in the toughness in the first half of the multicrystalline silicon block.

According to Hashin and Shtrikman [26], the presence of silicon carbide in the silicon matrix would also increase the elastic modulus of silicon. The results of the elastic modulus within the first half of the block are greater than the average elastic modulus of silicon, which is caused by the presence of silicon carbide and silicon nitride inclusions within the silicon matrix.

At the top part of the multicrystalline silicon block, silicon carbide inclusions appear to play a secondary role in breakage when the precipitation of the inclusions is not homogeneous. The sample in Fig. 19 broke during polishing, which was most likely due to cracks in the surrounding vicinity of aluminium inclusions (indicated by the letter 'a' in Fig. 19). However, initial fracture could have also occurred in the area indicated by the letter ' $b$ '. The precipitation of silicon carbide was concentrated within a volume of the material, most likely within one grain. This part of the material is very tough and will exhibit a high elastic modulus and fracture toughness. Therefore, stresses find a resistance to propagate through this material volume and concentrate in the surroundings of this area, which is free of silicon carbide inclusions. The area indicated by ' $b$ ' would concentrate the stress almost like a notch in the material; therefore, this area could have also been the fracture origin. 


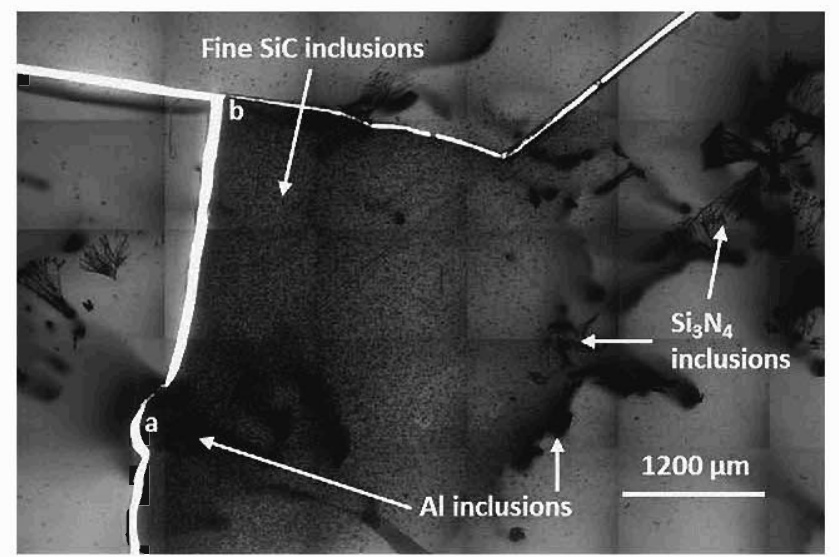

Fig. 19 Infrared light microscopy image of a polished silicon sample at the top part of the multicrystalline silicon block

\section{Conclusions}

The analysis of the experimental results presented in this work leads to the conclusion that inclusion impurities having considerably larger thermal expansion coefficients than silicon, such as aluminium, are the most detrimental type of defect for multicrystalline silicon used for solar applications. Circumferential micro-cracking occurs in the surroundings of the aluminium phases. Cracks represent the most severe type of defect, which control the mechanical strength of multicrystalline silicon, and they should be avoided.

Silicon nitride inclusions have a lower thermal expansion coefficient but a higher elastic modulus than silicon. The effect of the lower thermal expansion coefficient is more dominant than the higher elastic modulus. Therefore, silicon nitride inclusions cause failure by radial cracking in their surroundings. Silicon nitride increases the elastic modulus and decreases the fracture toughness of silicon wafers.

Silicon carbide is the least deleterious type of inclusion impurity. Silicon carbide has a higher thermal expansion coefficient and elastic modulus than silicon. These two properties increase both the fracture toughness and the elastic modulus of multicrystalline silicon. However, if the precipitation of the silicon carbide inclusions is not homogeneous within the material, failure can occur at the interface between areas with both high and low densities of silicon carbide inclusions.

Finally, it can be concluded that the content of aluminium in silicon feedstock should be kept at low levels to prevent the problems concerning the mechanical behaviour of silicon.

Acknowledgements The authors would like to deeply thank M. Kwiatkowska, F. Boldt, F. Haas, P. Häuber, M. Schumann, J.
Zielonka and M. Winterhalder from Fraunhofer ISE and W. Fütterer from the TU Bergakademie for their valuable work that made this research possible. This work was supported by the Fraunhofer Society with the project Si-Beacon, the Ministerio de Economia y Competitividad MAT2009-13979-C03, and the Comunidad de Madrid, S-S2009/MAT-1585-ESTRUMAT2.

\section{References}

Schmich E, Schillinger N, Reber S (2007) Silicon CVD deposition for low-cost applications in photovoltaics. Surf Coat Technol 201:9325-9329

Orellana Pérez T, Funke C, Fütterer W, Riepe S, Möller HJ, Tejado Garrido EM, Pastor JY (2011) In: "Impact of Impurities on the Mechanical Strength of Multicrystalline Silicon, 26th EU PVSEC, p 1864-1870

Green DJ, (1998) An introduction to the mechanical properties of ceramics, Cambridge University Press, Cambridge, p 1-136

Riepe S, Schumann M, Schmich E, Janz S, Eyer A, Reber S, Bett AW, Weber ER (2008) Silicon Material And Technology Evaluation Center (SIMTEC) at Fraunhofer ISE-Achievements and Visions, 23rd EU PVSEC, p 1264-1269

Funke C, Wolf S, Stoyan D (2009) Modelling the tensile strength and crack length of wire-sawn silic on wafers. J Sol Energy Eng 131 ASTM C1499-08 (2008) Standard Test Method for Monotonic Equibiaxial Flexural Strength of Advanced Ceramics at Ambient Temperature, ASTM, New York

ASTM C 1161-02 (2003) Standard test method for flexural strength of advanced ceramics at ambient temperature, ASTM, New York

ASTM C 1239-07 (2007) Standard practice for reporting uniaxial strength data and estimating weibull distribution parameters for advanced ceramics, ASTM, New York

Guinea GV, Pastor JY, Planas J, Elices M (1998) Stress intensity factor, compliance and CMOD for a general three-point-bend beam. Int J Fract 89:103-116

ASTM E 1876-09 (2009) Standard test method for dynamic young's modulus, shear modulus, and poisson's ratio by impulse excitation of vibration, ASTM, New York

Spinner S, Reichard TW, Tefft WE (1960) A comparison of experimental and theoretical relations between young's modulus and the flexural and longitudinal resonance frequencies of uniform bars. J Res Bur Stand 64:147-155

Wachtman JB, Roger Cannon W, Matthewson MJ (2009) In: Mechanical properties of ceramics, 2nd edn., Wiley, New Jeresy Selsing J (1961) Internal stresses in ceramics. J Am Ceram Soc 44:419

Weyl D (1959) Über den Einfluß innerer Spannungen auf das Gefuige und die mechanische Festigkeit des Porzellans. Ber Dtsch Keram Ges 36:319-324

Hull R (1999) Properties of crystalline silicon. IET, London

Davidge RW, Green TJ (1968) The strength of two phase ceramic/glass materials. J Mater Sci 3:629-634. doi: 10.1007/ BF00757910

Ito YM, Rosenblatt M, Cheng LY, Lange FF, Evans AG (1981) Cracking in particulate composites due to Thermal mechanical stress. Int J Fract 17:483-491

Evans AG (1974) The role of inclusions in the fracture of ceramic materials. J Mater Sci 9:1145-1152. doi: 10.1007/BF00552831

Green DJ (1981) Stress-induced microcracking at second-phase inclusions. J Am Ceram Soc 64:138-141

Goodier JN (1933) Concentration of stress around spherical and cylindrical inclusions and flaws. J Appl Mech 55:39-44 
Khaund AK, Krstic VD, Nicholson PS (1977) Influence of elastic and thermal mismatch on the local crack-driving force in brittle composites. J Mater Sci 12:2269-2273. doi: 10.1007/BF00552248 Li R, Chudnovsky A (1993) Variation of the energy release rate as a crack approches and passes through an elastic inclusion. Int $\mathrm{J}$ Fract 59:R69-R74

Wei GC, Becher PF (1984) Improvements in mechanical properties in SiC by the addition of TiC inclusions. J Am Ceram Soc 67:571-574

Rose LRF (1986) Effective fracture toughness of microcracked materials. J Am Ceram Soc 69:212-214

Hall JJ (1967) electronic effects in the elastic constants of n-type silicon. Phys Rev 161:756-761

Hashin Z, Shtrikman S (1963) A variational approach to the theory of the elastic behaviour of multiphase materials. J Mech Phys Solid 11:127-140

Budiansky B, O'Connoell RJ (1976) Elastic moduli of a cracked solid. Int J Solids Struct 12:81-97

Okada Y, Tokumaru Y (1984) Precise determination of lattice parameter and thermal expansion coefficient of silicon between 300 and 1500 K. J Appl Phys 56:314-320
Li Z, Bradt RC (1986) Thermal expansion of the cubic (3C) polytype of SiC. J Mater Sci 21:4366-4368

Iwai S, Yasunaga A (1959) Über die Thermische Ausdehnung des $\mathrm{Si}_{3} \mathrm{~N}_{4}$. Die Naturwissenschaften 46:473-474

Sakaguchi S, Murayama N, Kodama Y, Wakai F (1991) The poisson's ratio of engineering ceramics at elevated temperature. J Mater Sci Lett 10:282-284

Ashby MF (2004) Materials selection in mechanical design, 3rd edn. Butterworth Heinemann

Sinclair JE, Lawn BR (1972) An atomistic study of cracks in diamond-structure crystals. Proc Math Phys Eng Sci 329:83-103 Schönfelder S, Sampson A, Ganapati V, Koepge R, Bagdahn J, Buonassisi T (2009) Quantitative stress measurements of bulk microdefects in multicrystalline silicon, 24th EUPVSEC, p 977-980

M'Hamdi M, Gouttebroze S (2009) Analysis of the residual stress field associated with particles in multi-crystalline silicon, 24th EUPVSEC p 1265-1268 